\title{
Oncolytic adenovirus mediated Survivin RNA interference and 5-fluorouracil synergistically suppress the lymphatic metastasis of colorectal cancer
}

\author{
WEI SHEN ${ }^{1,2}$, JING-KAI TU ${ }^{3}$, XUE-HU WANG ${ }^{1,2}$ and ZHONG-XUE FU ${ }^{1}$ \\ ${ }^{1}$ Department of General Surgery and ${ }^{2}$ Key Laboratory of General Surgery, The First Affiliated Hospital, Chongqing Medical \\ University; ${ }^{3}$ Department of General Surgery, Ren Ji Hospital of Chongqing, Chongqing 400016, P.R. China
}

Received May 21, 2010; Accepted July 23, 2010

DOI: $10.3892 /$ or_00000984

\begin{abstract}
Colorectal cancer is one of the leading malignancies in the world. The mortality is mainly caused by tumor metastasis. It is urgent to find new therapeutics against metastatic colorectal cancer. We constructed an adenovirus carrying a Survivin targeted shRNA, tested its effects alone or with 5-fluorouracil (5-FU) both in vitro and in a nude mouse xenograft model. Results showed that the recombinant adenovirus reduced the expression of Survivin effectively, and administration of virus together with 5-FU inhibited cancer cell metastasis both in vitro and in vivo at concentrations at which each agent alone was ineffective. We conclude Survivin targeted virotherapy together with 5-FU chemotherapy may be a promising treatment for metastatic colorectal cancer.
\end{abstract}

\section{Introduction}

Colorectal cancer (CRC) is the second leading cause of cancer-related deaths in the US and the incidence is increasing rather rapidly in developing countries including China (1). Although traditional treatments for colorectal cancer such as surgical resection and chemotherapy have made improvement, the overall survival rate is not satisfactory because of tumor recurrence and metastasis (2-4). It is of great importance to find new therapeutics against metastatic colorectal cancer.

Adjuvant chemotherapy has now become the first line therapy for colorectal cancer and 5-FU is the most effective systemic chemotherapeutic agent in the management of advanced colorectal cancer by inducing apoptosis $(5,6)$. However, 5-FU itself alone does not substantially improve survival rates. Moreover, severe toxic side effect is the major

Correspondence to: Dr Zhong-Xue Fu, Department of General Surgery, The First Affiliated Hospital, Chongqing Medical University, Chongqing 400016, P.R. China

E-mail: fzx_cqmu@hotmail.com

Key words: virotherapy, colorecatal carcinoma, 5-FU, metastasis clinical obstacle associated with 5-FU therapy. The dosage that is necessary to overcome even a small increase in cellular resistance can result in severe cytotoxicity in normal cells. When combined with biological or radiation therapy, 5-FU usually shows synergistic effects (7).

Oncolytic virus virotherapy has been proved by many studies to be effective against various types of malignancies (8-11). ONYX-015, a well known E1B-55 kDa deleted adenovirus, has been used in clinical trials and achieved encouraging results, but the therapeutic efficacy of ONYX015 is limited when used alone $(12,13)$. In our previous study, we constructed an E1B-55 kDa deleted adenovirus similar to ONYX-015 carrying an shRNA against Survivin, which showed obvious inhibition effects specifically on tumor cells (14). We hypo-thesized this construct may show more potent effects when combined with 5-FU chemotherapy because they both induce apoptosis but in different mechanisms. Interestingly, we found combined treatment with both oncolytic virotherapy and chemotherapy significantly suppressed the metastatic ability of LoVo cell both in vitro and in vivo. This novel modality may provide a promising treatment for metastatic colorectal cancer patients.

\section{Materials and methods}

Cell lines and cell culture. Human colon adenocacinoma cell line LoVo and SW480 were obtained from Shanghai Cell Collection (Shanghai, China). HEK293 cell was purchased from Microbix Biosystems Inc. and they were routinely cultured in Dulbecco's modified Eagle's media (Gibco, Carlsbad, CA, USA) supplemented with $10 \%$ (vol/vol) fetal bovine serum (Gibco) at $37^{\circ} \mathrm{C}$ in a humidified incubator containing $5 \% \mathrm{CO}_{2}$.

Construction of Survivin shRNA expression plasmid. A pair of short hairpin RNA (shRNA) targeting Survivin (GeneBank accession NM_001168) which has been reported (6) was constructed. The sequence was a 19nt small interfering RNA: GGCTGGCTTCATCCACTGC (86-104) with a ring sequence of 9 base pairs connecting the sense and antisense strands (TTCAAGAGA). The shRNA was constructed into pMD-18T plasmid (Takara), namely pMD-18T-S. The sequence was not homologous with any human coding gene by BLAST analysis. 
Adenovirus construction. An E1b-55kDa deleted oncolytic adenoviruse was constructed and reserved in our laboratory. Briefly, pIRES-EGFP (Clontech) was cut with EcoRI and $X b a \mathrm{I}$ to get the EGFP fragment. Then the EGFP segment was ligated into pCA13 (Microbix Biosystems) to form pCA13EGFP. After that, the Survivin shRNA expression cassette was excised from pMD-18T-Sur with XhoI and BamHI, first subcloned into pCA13-EGFP to form pCA13-Sur-EGFP. Then the expression cassette containing the Survivin shRNA controlled by the human CMV promoter and reporter gene EGFP were cut with $B g l I I$ and subcloned into pZD55 to construct pZD55-Sur-EGFP. Oncolytic adenoviruses ZD55Sur-EGFP was generated by homologous recombination between pZD55-Sur-EGFP and the adenovirus packaging plasmid pBHGE3 (Microbix Biosystems). Viruses were purified by ultracentrifugation with cesium chloride gradient according to standard technique. The titers were determined by cytopathic effect (CPE) on HEK293 cells in a 96-well plate by a fluorescence microscope.

Western blot analysis. Cells were treated with adenovirus and/or 5-FU and were incubated for $48 \mathrm{~h}$ and then harvested. The protein extracts were separated via sodium dodecyl sulfate-polyacdene gel electrophoresis and transferred onto nitrocellulose membranes. The membrane was then blocked with the primary polycolonal antibody against Survivin and $B$-actin (rabbit anti-human, Santa Cruz, CA) at $4^{\circ} \mathrm{C}$ overnight. After washing with PBS containing $0.05 \%$ Tween-20 the membranes were incubated with secondary antibody (goat anti-rabbit, Santa Cruz) for $2 \mathrm{~h}$. They were visualized by chemiluminescence system according to manufacturer's instruction.

Cell viability assay. Cells were seeded in 96-well plates for $24 \mathrm{~h}$ at $1 \times 10^{4}$ per well and treated with adenovirus, 5-FU or a combination of the virus and 5-FU at the indicated MOIs or drug dosages. After indicated time of incubation, $15 \mu 1$ 3-(4,5-dimethylthiazol-2-yl)-2,5-diphenyltetrazolium bromide (MTT) $(5 \mathrm{mg} / \mathrm{ml}$ in PBS) was added to each well for $4 \mathrm{~h}$ incubation at $37^{\circ} \mathrm{C}$ followed by the addition of $150 \mu 1$ DMSO. Absorbance at $570 \mathrm{~nm}$ was measured for cell viability in each well.

In vitro cell migration and invasion assays. Cell migration was evaluated in 24-well transwell chambers (Corning) with upper and lower compartments separated by polycarbonate membranes with $8-\mu \mathrm{m}$ pores. The bottom chamber was filled with Dulbecco's modified Eagle's media supplemented with $10 \%$ fetal bovine serum as a chemoattractant. Pretransfected cells with or without 5-FU were plated in the upper chamber and incubated for $24 \mathrm{~h}$ at $37^{\circ} \mathrm{C}$ in a humidified incubator containing $5 \% \mathrm{CO}_{2}$. The cells remained at the upper surface of the membrane were removed with a cotton swab. The cells that migrated through the pores were fixed with methanol and stained with crystal violet. Cell numbers were counted in 5 separate fields using light microscopy at X200 magnification.

In a similar fashion, the invasiveness of LoVo and SW480 cells were determined using Geltrex ${ }^{\mathrm{TM}}$ (Invitrogen) coated 24-well transwell chambers. Serum deprived cells were added to the upper surface of each chamber. The bottom chamber

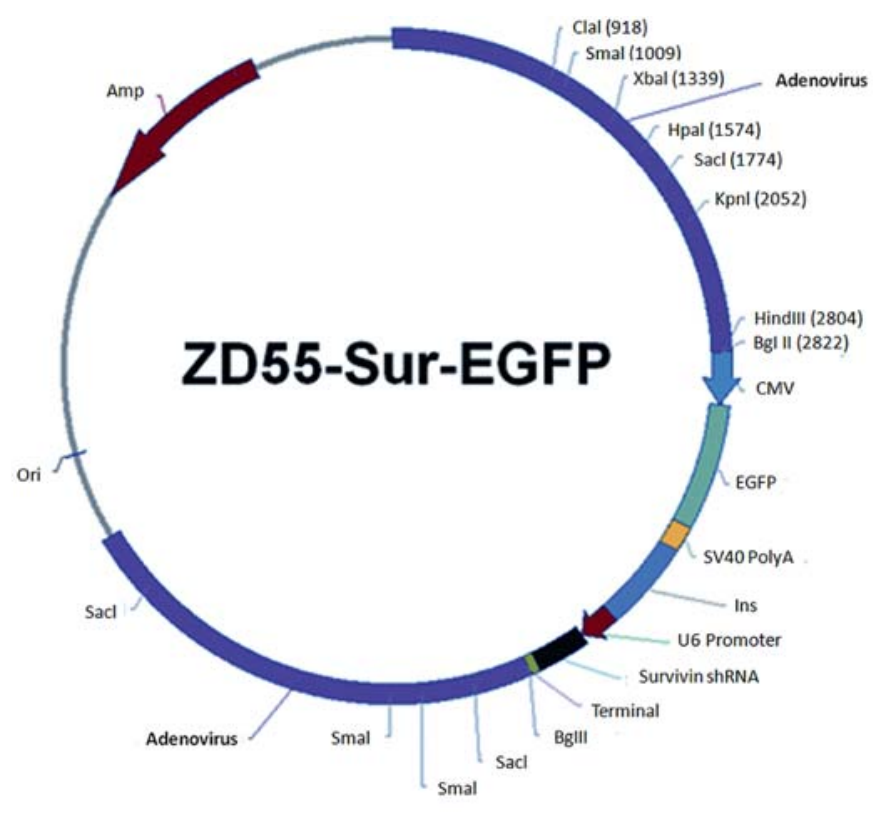

Figure 1. The schematic presentation of ZD55-Sur-EGFP. The E1B-55 kDa gene was replaced by Survivin-shRNA sequence expression cassette and EGFP.

was filled with DMEM containing 10\% FBS. Cells were allowed $24 \mathrm{~h}$ to migrate to the underside of the membrane. Non-invading cells were removed by wiping the upper side of the membrane and the invaded cells were fixed, stained and counted in the manner mentioned above.

Animal studies. Five-week-old, female BALBC/C nude mice were obtained from the Laboratory Animal Center of Chongqing Medical University. They were maintained in the specific pathogen-free unit under isothermal conditions. All experimental procedures were carried out in accordance with the National Institute of Health Guide for the Care and Use of Laboratory Animals.

A foot pad colorectal carcinoma model was established as described previously by Harrell et al (15). Briefly, $5 \times 10^{5}$ SW480 cells suspended in $50 \mu 1$ serum-free medium was injected into the foot pad of the hind leg. When tumors size reached about $100 \mathrm{~mm}^{3}$, mice were randomly divided into 4 groups with 6 mice in each group. ZD-Sur-EGFP and ZD-EGFP were injected through the tail vein with $2 \times 10^{7} \mathrm{PFU}$ adenoviruses suspended in $50 \mu 1$ PBS or $50 \mu 1$ PBS alone for consecutive 3 days. 5-FU was intraperitoneally injected with 5-FU (Sigma, $80 \mu \mathrm{g} /$ body) everyday for 5 days. The volume of tumor was calculated by the formula: $\mathrm{V}\left(\mathrm{mm}^{3}\right)=$ length $\mathrm{x}$ width $2 / 2$. Consecutive sections were made for every removed lymph node and stained with hematoxylin-eosin to identify whether lymphatic metastasis exists.

Statistical analysis. ANOVA or analysis of weighted least squares estimates were used for statistical analysis as appropriate. Differences were considered significant at $\mathrm{P}<0.05$. The data are represented as mean $\pm \mathrm{SD}$, unless otherwise indicated. All experiments were repeated in triplicate. 
SW480

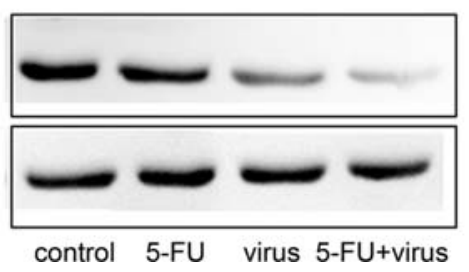

LoVo

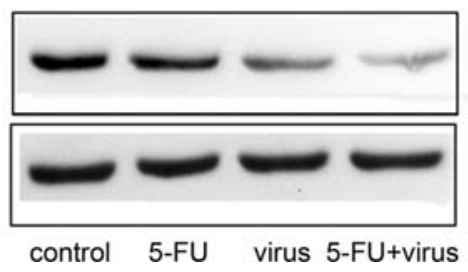

Figure 2. Cells were treated with 5-FU $(0.5 \mu \mathrm{g} / \mathrm{ml})$ or ZD55-Sur-EGFP $(0.1 \mathrm{MOI})$ respectively or in combination and then the cell extract was subjected to immunoblotting to detect the Survivin protein expression. In both SW480 90 (A) and LoVo (B) cells, the Survivin expression was suppressed by ZD55-SurEGFP, whereas low concentration of 5-FU did not affect the expression of Survivin.
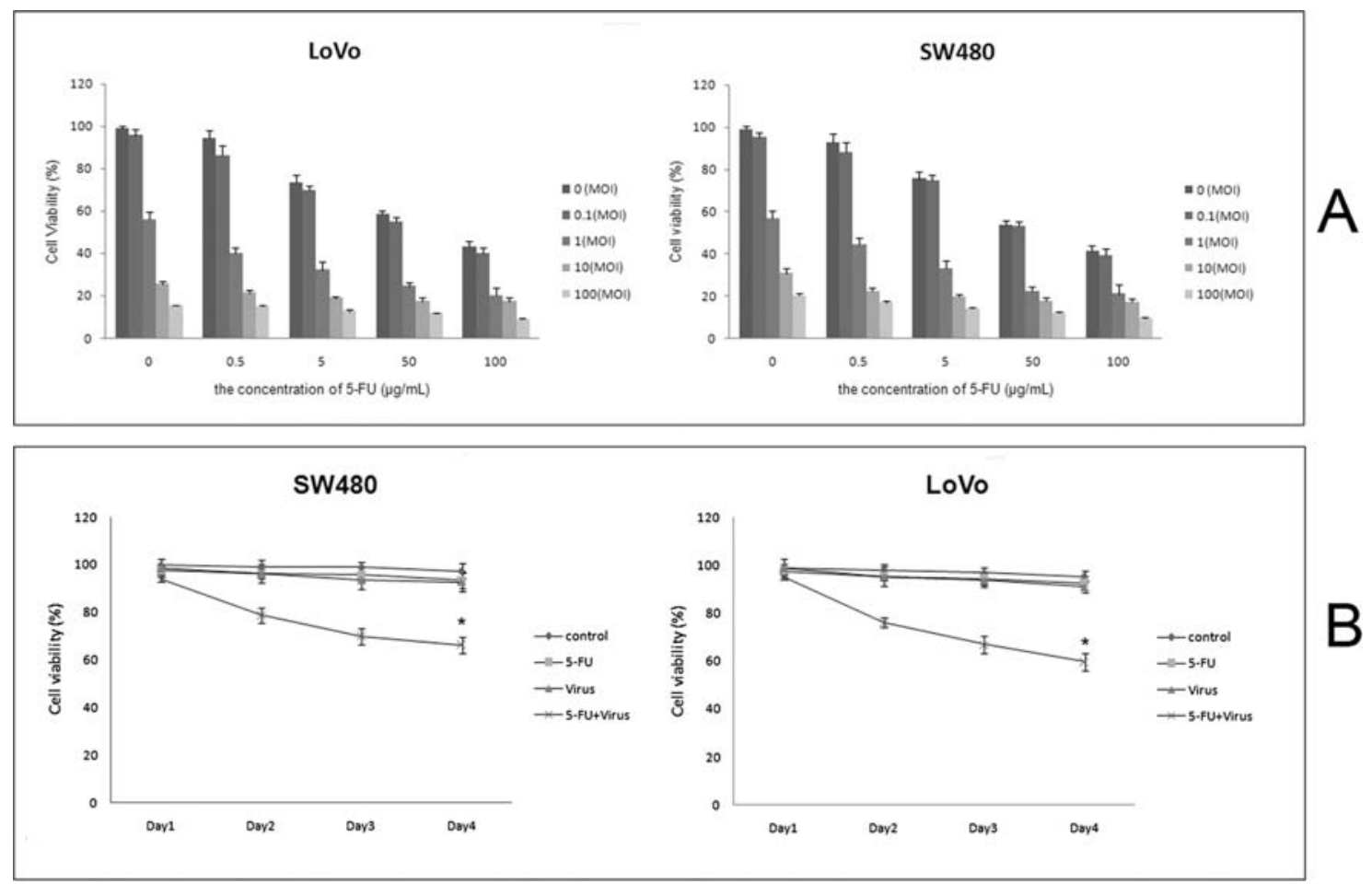

Figure 3. Cell viability assay was performed to examine the combinatory effect of ZD55-Sur-EGFP and 5-FU. (A) Low dosages of virus (0.1 MOI) or 5-FU $(\mu \mathrm{g} / \mathrm{ml})$ had no effect on cell viability in the cells. But a combination of virus and 5-FU suppressed the growth of colorectal cancer cells in a dose-dependent manner. (B) A combination of virus $(0.1 \mathrm{MOI})$ and $5-\mathrm{FU}(\mu \mathrm{g} / \mathrm{ml})$ suppressed the cell viability in a time-dependent manner. $\mathrm{P}<0.01 \mathrm{vs}$. other groups.

\section{Results}

Adenovirus construction and identification. Recombinant oncolytic adenovirus ZD55-Sur-EGFP was constructed by homologous recombination of pZD55-Sur-EGFP and the packaging plasmid $\mathrm{pBHGE3}$. The schematic picture shows the recombinant ZD55-Sur-EGFP (Fig. 1). The result was confirmed by restrictive enzyme digestion assay and sequence assay.

Reduction of Survivin expression. Western blot analysis was performed $48 \mathrm{~h}$ after treatment. Cotreatment of ZD55-SurEGFP and 5-FU showed no significant difference in downregulating Survivin expression when compared with ZD55Sur-EGFP alone (Fig. 2).

Cell viability was suppressed by combination of low dosages of adenovirus and 5-FU. LoVo and SW480 cells were infected with ZD55-Sur-EGFP or 5-FU respectively or in combination. The result showed that both virus and 5-FU decreased the cell viability in a dose-dependent manner (Fig. 3A). On the basis of a previous report showing that subtumoricidal dosages $(4 \mu \mathrm{M}, \sim 0.5 \mu \mathrm{g} / \mathrm{ml})$ of $5-\mathrm{FU}$ treatment facilitated the replication of an adenovirus but by itself did not show any antiproliferative activity $(16,17)$, we selected the dose of $0.5 \mu \mathrm{g} / \mathrm{ml} 5$-FU to evaluate the synergistic cytopathic effects of ZD55-Sur-EGFP and 5-FU and the result is shown in Fig. 3B. The viability of tumor cells in the co-treated group was significantly inhibited compared to other groups.

Effects of oncolytic virus and 5-FU on tumor cell metastasis in vitro. The migration and metastatic potential of tumor cells were evaluated by transwell assay. As shown in Fig. 4, the migration and metastasis of 5-FU and oncolytic virus treated group was obviously attenuated, suggesting that the migratory 

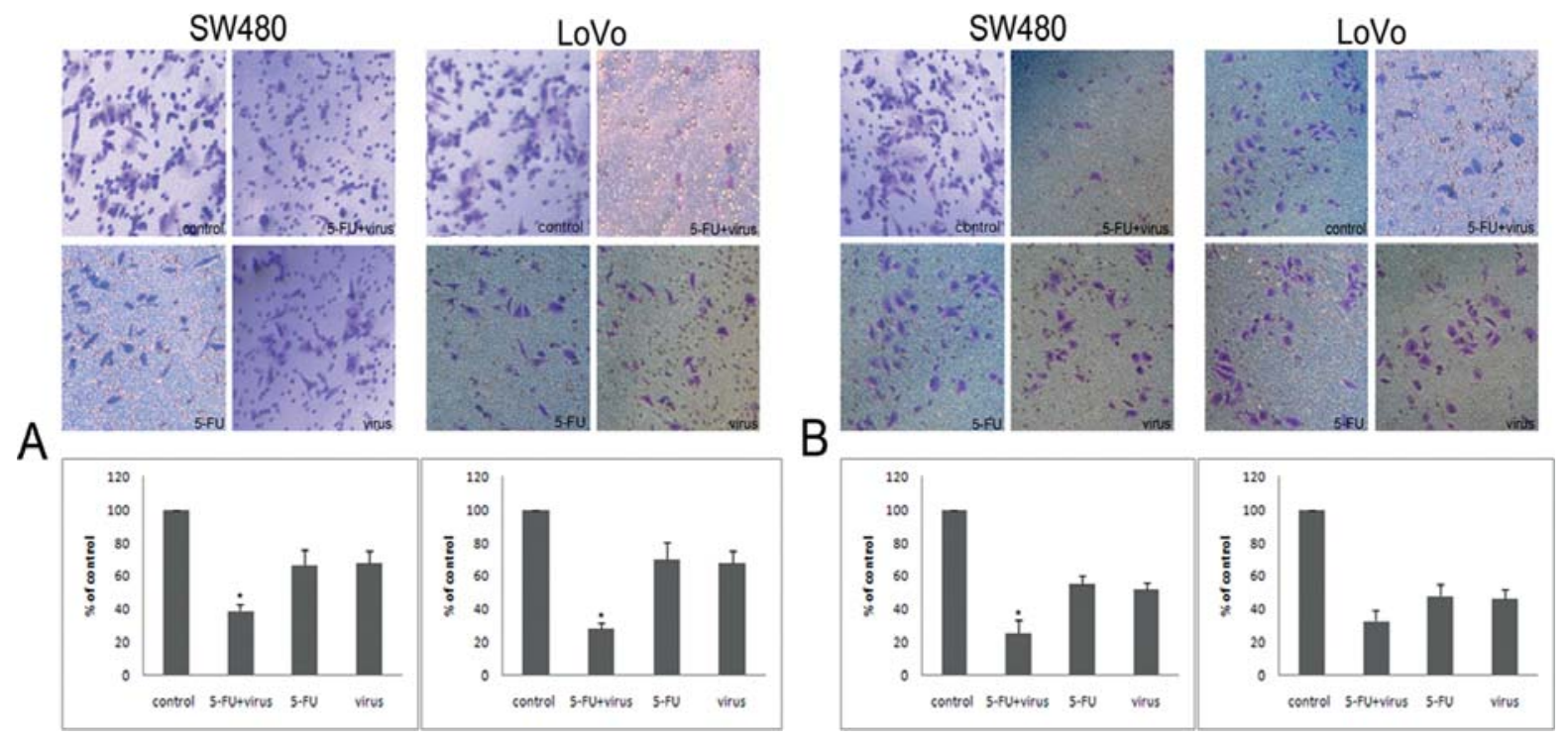

Figure 4. The migratory and invasive potential of tumor cells were inhibited. (A) In both cell lines, the number of cells migrated to the other side of the membrane were significantly fewer than the control group. (B) Similar result was achieved in the Geltrex coated transwell assay. The invasiveness of cells were inhibited in virus and 5-FU cotreated group. ${ }^{*} \mathrm{P}<0.05$.

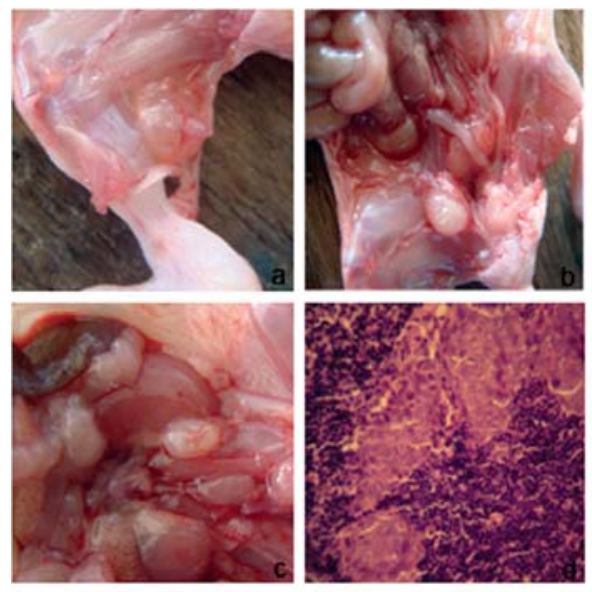

A

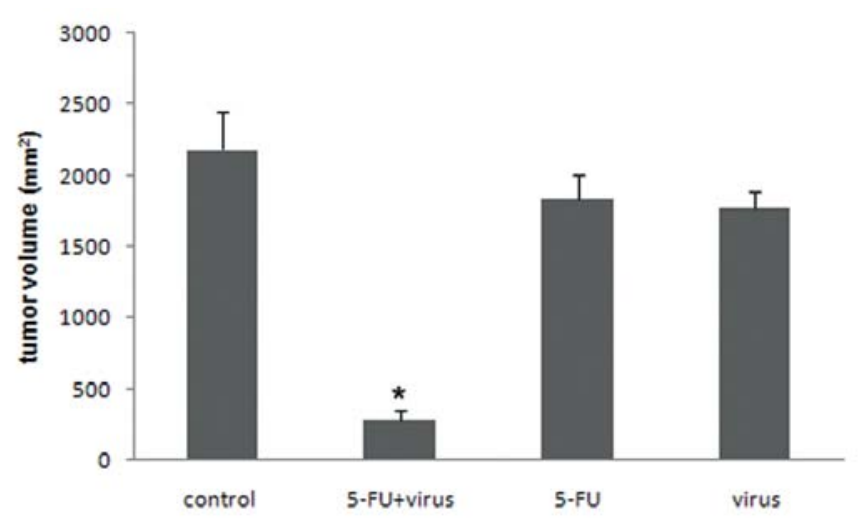

B

Figure 5. (A) The sentinel lymph nodes with metastasis. (a) Popliteal lymph node. (b) Inguinal lymph node. (c) Perinephral lymph node. (d) Hematoxylineosin staining of the lymph node. (B) Tumor volume was quantitatively represented. Data were expressed as mean $\pm \mathrm{SD}$. ${ }^{*} \mathrm{P}<0.01$ vs. other groups. $\rightarrow$ Sentinel lymph node with metastasis.

Table I. The sentinel lymph node metastasis in different groups.

\begin{tabular}{lccc}
\hline & Popliteal & Inguinal & Perinephral \\
\hline Control & 6 & 6 & 4 \\
5-FU+virus & 2 & 1 & 0 \\
5-FU & 6 & 6 & 3 \\
Virus & 6 & 6 & 4 \\
\hline
\end{tabular}

${ }^{\mathrm{a}} \mathrm{P}<0.001$ vs. other groups. and invasive potential of LoVo cell was significantly decreased after the treatment.

Inhibition of tumor growth and lymphatic metastasis in xenograft model. We next investigated the effect of the virus and 5-FU in vivo to determine whether this combination was still effective. When the tumor size reached $100 \mathrm{~mm}^{3}$, the mice were treated with subtumoricidal dosages of ZD55-Sur-EGFP and 5 -FU $\left(2 \times 10^{7} \mathrm{PFU}\right.$ and $80 \mu \mathrm{g} /$ body $)$ respectively or in combination. Results showed the combination administration could significantly decrease both tumor volume (Fig. 5) and lymph node metastasis (Table I). The average tumor volume 
in 5-FU and virus group was $283.6 \mathrm{~mm}^{2}$, which was significantly smaller than the control group $\left(2184.7 \mathrm{~mm}^{2}\right), 5-\mathrm{FU}$ group $\left(1836.3 \mathrm{~mm}^{2}\right)$ and virus treated group $\left(1767.6 \mathrm{~mm}^{2}\right)$.

\section{Discussion}

Colorectal carcinoma is the most frequent alimentary system malignancy, which accounts for $40 \%$ of the estimated new cancer cases of the digestive tract (18). Although the incidence of CRC in developed countries is slowly decreasing, it is increasing rapidly in developing countries. Despite the advances in diagnostic and therapeutic methodologies, the prognoses of metastatic colorectal cancer patients still remain poor. The mortality of CRC is mainly due to the high metastatic potential of tumor cells and the urgent to establish a more effective therapeutic modality for metastatic CRC.

Survivin gene is highly expressed in human colorectal cancer and has a close relationship with the prognosis. There are several reports on close relationship between the Survivin expressed by tumor tissue and staging, prognosis of the patients. Miyachi et al found the level of survivin mRNA expression may indicate the potential for lymph node metastasis in patients with gastric cancer (19). Yie and his colleagues concluded the detection of circulating cancer cells expressing Survivin mRNA could be used to accurately identify gastric and colorectal cancer patients with high risks of relapse (20). A recent study by Zhang et al indicated that Survivin was significantly correlated with clinical staging and lymph node metastasis in thyroid carcinoma (21).

Some studies have sought to stimulate apoptosis of tumor cells. A series of investigations including ours has generated oncolytic adenoviruses from the same backbone with different proapoptotic transgenes and demonstrated significant inhibitory effect both in vitro and in animal models $(14,22)$. Some of these have succeeded in inducing synergistic oncolytic effects by combining virotherapy with the chemotherapeutic agents such as 5-FU and cisplatin $(7,23,24)$. Based on these results, we carried out our study on a combined therapy using armed adenovirus and 5-FU against colorectal cancer cells

In our previous study, we showed that oncolytic adenovirus carrying a Survivin shRNA significantly attenuated the growth of cancer cells both in vitro and in vivo. However, due to the transient nature of adenovirus expression and the immune response against the adenovirus $(25,26)$, it is necessary to find a better approach to circumvent this shortcoming.

In this study, we combined armed oncolytic adenovirus virotherapy with 5-FU chemotherapy, and tested their effects on human colorectal cancer cell lines. The results showed a synergistic effect even though both agents were at low dosage. In our present study, colorectal cell lines were treated with ZD55-Sur-EGFP or 5-FU and dose-dependent cytotoxicity was observed. Then we chose the maximal concentrations for both agents that would not lead to significant cell death to examine the migration and metastasis of tumor cells. The result indicated the migratory and metastatic potential of tumor cells were significantly attenuated.
Lymphatic metastasis is the most primary pathway for colon cancer metastasis. To test the synergistic effect in vivo, we directed our animal studies to investigate the effects of 5-FU and adnovirus on lymphatic metastasis. Certain advantages and limitations are associated with both spontaneous and experimental models of tumor metastasis and no single system can model the exact biological environment that is encountered during human tumorigenesis and progression. We selected a foot pad model of lymphatic metastasis for multiple reasons (27). First, the model has been well established and described. Moreover, this model simulated the development of lymphatic metastasis with multiple sentinel lymph nodes which is convenient for evaluating the treatment $(15,28)$. Using this model we demonstrated the growth of xenograft tumors and lymph node metastasis were obviously attenuated even when both 5-FU and oncolytic adenovirus were at very low dosage.

Despite the encouraging results, the limitation of this research is that it does not explain the mechanism underlying the synergy. However, this research indicates a promising modality for metastatic CRC.

\section{Acknowledgements}

This study is supported by grants from the National Natural Science Foundation of China (No. 30772547) and Doctoral Fund of Ministry of Education of China (No. 20060631013). We thank Key Laboratory of Opthalamology, Chongqing Medical University for equipment support.

\section{References}

1. Parkin DM, Bray F, Ferlay J and Pisani P: Global cancer statistics, 2002. CA Cancer J Clin 55: 74-108, 2005.

2. Joosten J, Jager G, Oyen W, Wobbes T and Ruers T: Cryosurgery and radiofrequency ablation for unresectable colorectal liver metastases. Eur J Surg Oncol 31: 1152-1159, 2005.

3. Gravalos C, García-Sanchez L, Hernandez M, Holgado E, Alvarez N, García-Escobar I, Martínez J and Robles L: Surgical resection of a solitary pancreatic metastasis from colorectal cancer: a new step to a cure? Clin Colorectal Cancer 7: 398-401, 2008.

4. Renouf D, Kennecke H and Gill S: Trends in chemotherapy utilization for colorectal cancer. Clin Colorectal Cancer 7: 386-389, 2008.

5. André T, Boni C, Mounedji-Boudiaf L, Navarro M, Tabernero J, Hickish T, Topham C, Zaninelli M, Clingan P, Bridgewater J, Tabah-Fisch I and De Gramont A: Oxaliplatin, fluorouracil and leucovorin as adjuvant treatment for colon cancer. N Engl J Med 350: 2343-2351, 2004.

6. Sauer R, Becker H, Hohenberger W, Rödel C, Wittekind C, Fietkau R, Martus P, Tschmelitsch J, Hager E, Hess CF, Karstens JH, Liersch T, Schmidberger H and Raab R: Preoperative versus postoperative chemoradiotherapy for rectal cancer. N Engl J Med 351: 1731-1740, 2004.

7. Zhang Y, Qin X, Zhang Y, Zhao L, Wang Y, Liu X and Yao L: Combination of ZD55-MnSOD therapy with 5-FU enhances antitumor efficacy in colorectal cancer. J Cancer Res Clin Oncol 134: 219-226, 2008.

8. Hsu KF, Wu CL, Huang SC, Hsieh JL, Huang YS, Chen YF, Shen MR, Chung WJ, Chou CY and Shiau AL: Conditionally replicating E1B-deleted adenovirus driven by the squamous cell carcinoma antigen 2 promoter for uterine cervical cancer therapy. Cancer Gene Ther 15: 526-534, 2008.

9. Wang ZG, Zhao W, Ramachandra M and Seth P: An oncolytic adenovirus expressing soluble transforming growth factor-beta type II receptor for targeting breast cancer: in vitro evaluation. Mol Cancer Ther 5: 367-373, 2006. 
10. Cui Q, Jiang W, Wang Y, Lv C, Luo J, Zhang W, Lin F, Yin Y, Cai R, Wei P and Qian C: Transfer of suppressor of cytokine signaling 3 by an oncolytic adenovirus induces potential antitumor activities in hepatocellular carcinoma. Hepatology 47: 105-112, 2008.

11. Kanerva A, Lavilla-Alonso S, Raki M, Kangasniemi L, Bauerschmitz GJ, Takayama K, Ristimäki A, Desmond RA and Hemminki A: Systemic therapy for cervical cancer with potentially regulatable oncolytic adenoviruses. PLoS One 3: e2917, 2008.

12. Khuri FR, Nemunaitis J, Ganly I, Arseneau J, Tannock IF Romel L, Gore M, Ironside J, MacDougall RH, Heise C, Randlev B, Gillenwater AM, Bruso P, Kaye SB, Hong WK and Kirn DH: A controlled trial of intratumoral ONYX-015, a selectively-replicating adenovirus, in combination with cisplatin and 5-fluorouracil in patients with recurrent head and neck cancer. Nat Med 6: 879-885, 2000

13. Heise C, Sampson-Johannes A, Williams A, McCormick F, von Hoff DD and Kirn DH: ONYX-015, an E1B gene-attenuated adenovirus, causes tumor-specific cytolysis and antitumoral efficacy that can be augmented by standard chemotherapeutic agents. Nat Med 3: 639-645, 1997.

14. Shen W, Wang CY, Wang XH and Fu ZX: Oncolytic adenovirus mediated Survivin knockdown by RNA interference suppresses human colorectal carcinoma growth in vitro and in vivo. J Exp Clin Cancer Res 28: 81, 2009.

15. Harrell MI, Iritani BM and Ruddell A: Tumor-induced sentinel lymph node lymphangiogenesis and increased lymph flow precede melanoma metastasis. Am J Pathol 170: 774-786, 2007.

16. Bernt KM, Steinwaerder DS, Ni S, Li ZY, Roffler SR and Lieber A: Enzyme-activated prodrug therapy enhances tumorspecific replication of adenovirus vectors. Cancer Res 62: 6089-6098, 2002

17. Nakano K, Todo T, Zhao G, Yamaguchi K, Kuroki S, Cohen JB, Glorioso JC and Tanaka M: Enhanced efficacy of conditionally replicating herpes simplex virus (G207) combined with 5fluorouracil and surgical resection in peritoneal cancer dissemination models. J Gene Med 7: 638-648, 2005.

18. Jemal A, Siegel R, Ward E, Hao Y, Xu J, Murray T and Thun MJ: Cancer statistics, 2008. CA Cancer J Clin 58: 71-96, 2008.

19. Miyachi K, Sasaki K, Onodera S, Taguchi T, Nagamachi M, Kaneko $\mathrm{H}$ and Sunagawa M: Correlation between survivin mRNA expression and lymph node metastasis in gastric cancer, Gastric Cancer 6: 217-224, 2003.
20. Yie SM, Lou B, Ye SR, Cao M, He X, Li P, Hu K, Rao L, Wu SM, Xiao HB and Gao E: Detection of survivin-expressing circulating cancer cells (CCCs) in peripheral blood of patients with gastric and colorectal cancer reveals high risks of relapse. Ann Surg Oncol 15: 3073-3082, 2008.

21. Zhang HY, Meng X, Du ZX, Fang CQ, Liu GL, Wang HQ and Deng WW: Significance of survivin, caspase-3 and VEGF expression in thyroid carcinoma. Clin Exp Med 9: 207-213, 2009.

22. Zheng JN, Pei DS, Mao LJ, Liu XY, Mei DD, Zhang BF, Shi Z, Wen RM and Sun XQ: Inhibition of renal cancer cell growth in vitro and in vivo with oncolytic adenovirus armed short hairpin RNA targeting Ki-67 encoding mRNA. Cancer Gene Ther 16: 20-32, 2009.

23. Wu YM, Zhang KJ, Yue XT, Wang YQ, Yang Y, Li GC, Li N and Wang YG: Enhancement of tumor cell death by combining cisplatin with an oncolytic adenovirus carring MDA-7/IL-24. Acta Pharmacol Sin 30: 467-477, 2009.

24. Chu L, Gu J, Sun L, Qian Q, Qian C and Liu X: Oncolytic adenovirus-mediated shRNA against Apollon inhibits tumor cell growth and enhances antitumor effect of 5-fluorouracil. Gene Ther 15: 484-494, 2008.

25. Carette JE, Overmeer RM, Schagen FH, Alemany R, Barski OA, Gerritsen WR and van Beusechem VW: Conditionally replicating adenoviruses expressing short hairpin RNAs silence the expression of a target gene in cancer cells. Cancer Res 64: 2663-2667, 2004

26. Bangari DS and Mittal SK: Current strategies and future directions for eluding adenoviral vector immunity. Curr Gene Ther 6: 215-226, 2006

27. Wai PY, Mi Z, Guo H, Sarraf-Yazdi S, Gao C, Wei J, Marroquin CE, Clary B and Kuo PC: Osteopontin silencing by small interfering RNA suppresses in vitro and in vivo CT26 murine colon adenocarcinoma metastasis. Carcinogenesis 26: 741-751, 2005

28. Brader P, Kelly K, Gang S, Shah JP, Wong RJ, Hricak H, Blasberg RG, Fong Y and Gil Z: Imaging of lymph node micrometastases using an oncolytic herpes virus and [18F]FEAU PET. PLoS One 4: e4789, 2009. 